\title{
Additive-Free Rice Starch-Assisted Synthesis of Spherical Nanostructured Hematite for Degradation of Dye Contaminant
}

\author{
Juan Matmin ${ }^{1, * D}$, Irwan Affendi ${ }^{1}$, Salizatul Ilyana Ibrahim ${ }^{1}$ and Salasiah Endud ${ }^{2} \mathbb{D}$ \\ 1 Centre of Foundation Studies UiTM, Universiti Teknologi MARA (UiTM), Cawangan Selangor, \\ Kampus Dengkil, 43800 Dengkil, Selangor, Malaysia; affendi7848@puncakalam.uitm.edu.my (I.A.); \\ saliza2910@puncakalam.uitm.edu.my (S.I.I.) \\ 2 Chemistry Department, Faculty of Science, Universiti Teknologi Malaysia (UTM), \\ 81310 Skudai, Johor, Malaysia; salasiah@kimia.fs.utm.my \\ * Correspondence: juanmatmin@puncakalam.uitm.edu.my; Tel.: +60-389-245-449
}

Received: 20 August 2018; Accepted: 5 September 2018; Published: 8 September 2018

\begin{abstract}
Nanostructured hematite materials for advanced applications are conventionally prepared with the presence of additives, tainting its purity with remnants of copolymer surfactants, active chelating molecules, stabilizing agents, or co-precipitating salts. Thus, preparing nanostructured hematite via additive-free and green synthesis methods remains a huge hurdle. This study presents an environmentally friendly and facile synthesis of spherical nanostructured hematite (Sp-HNP) using rice starch-assisted synthesis. The physicochemical properties of the Sp-HNP were investigated by Fourier-transform infrared spectroscopy (FTIR), X-ray diffraction (XRD), thermogravimetric analysis (TGA), field emission scanning electron microscopy (FESEM), energy dispersive X-ray spectroscopy (EDX), transmission electron microscopy (TEM), UV-Vis diffuse reflectance spectroscopy (DR UV-Vis), and nitrogen adsorption-desorption analysis. The Sp-HNP showed a well-crystallized structure of pure rhombohedral phase, having a spherical-shaped morphology from 24 to $48 \mathrm{~nm}$, and a surface area of $20.04 \mathrm{~m}^{2} / \mathrm{g}$. Moreover, the Sp-HNP exhibited enhanced photocatalytic degradation of methylene blue dye, owing to the large surface-to-volume ratio. The current work has provided a sustainable synthesis route to produce spherical nanostructured hematite without the use of any hazardous agents or toxic additives, in agreement with the principles of green chemistry for the degradation of dye contaminant.
\end{abstract}

Keywords: iron oxide; rice starch; templating method; hematite; additive-free synthesis; spherical structures; nanoparticles; nanostructured materials

\section{Introduction}

Iron oxide nanoparticles (IONPs) in the form of magnetite, maghemite, lepidochrocite, goethite, akageneite, and hematite have emerged in advanced applications of medical processes, biotechnology, sensors, data storage, pigments, fine ceramics, photo/electrochemical cells, wastewater treatment, and catalysts [1-4]. Amongst all IONPs, hematite nanoparticles (HNPs) show the most prominent catalytic activity for organic transformation or degradation reactions, depending on the shape synthesized. The potential of a HNP can be further enhanced as a high-performance catalyst, which delivers good conversion activity, specific selectivity, and reliable stability simply by changing the exposed crystal facet via shape tailoring [5]. In recent years, a variety of synthetic methods have been investigated to produce HNPs using different approaches of physical synthesis (laser ablation arc discharge, combustion, ultrasound irradiation, electrodeposition, and pyrolysis) [6], biological synthesis (plant extracts, bacterium, yeast, fungus, and algae) [7] and chemical methods (sol-gel 
synthesis, the reverse micelle method, and hydrothermal methods) [8]. However, these methods have mainly yielded disordered or irregular-shaped nano/macro-sized HNP morphologies that create severe agglomeration, such as bitruncated polygons [8,9] and pseudo-peanut shapes [10]. Therefore, significant efforts have been devoted to controlling the morphology of HNPs by employing different synthesis and processing routes. Today, HNPs are prepared in different regular shapes and defined morphologies, such as nanocuboids, nanowhiskers, nanorods, ovals, cubes, rhombohedral shapes, and spherical morphologies [11,12]. Nevertheless, most of the preparation methods are less favored due to the complexity of the optimization process and the presence of multiple variables.

Preferably, HNPs with ordered morphologies should be prepared from the co-precipitation method (a wet chemical synthesis), which is simple, efficient, and tractable, in which the size, shape, and even morphology of the particles can be tailored [6]. To obtain well-crystallized HNPs with ordered morphologies, this method strongly depends on the use of additives such as copolymer surfactants (pluronic, F88, F127, P123, and polyvinylpyrrolidone), surface active structures from chelating compounds (thiols-based molecules), and stabilizing agents (triethylamine and $\left(\mathrm{NH}_{2}\right)_{2} \mathrm{CO}$ of urea), as well as co-precipitating salts (sodium acetate or NaAc) [13-16]. Unfortunately, the presence of additives significantly affects not only the morphology and percentage yield, but also drastically decreases the HNPs' purity due to the large amounts of byproducts, such as b-FeOOH, $\mathrm{Fe}_{3} \mathrm{O}_{4}$, or $\mathrm{g}-\mathrm{Fe}_{2} \mathrm{O}_{3}$ [17], and the salts' impurities, such as with ferric and ferrous salts [18]. Alternatively, to overcome such problems, additive-free syntheses of HNPs have been proposed [19], using greener and more benign reagents from biomaterials templates, such as starch. These methods avoid the use of additives, which commonly promote the presence of impurities from the incomplete conversion of the salts' precursors into HNPs. The use of starch as a template has been reported in a number of previous studies [19]. This includes the use of starch as a template by using starch-coordinated Fe as the mixture of capping agents and, subsequently, the removal of the template by controlled heat treatment. In spite of that, the approach only produces highly agglomerated and disordered hematite macroparticles (greater than $1000 \mathrm{~nm}$ ) with limited functionality [20]. This is due to the presence of organic remnants, originating from the mixtures of the capping agent used, which is strongly bound to the HNPs. It is well-known that the use of starch-assisted synthesis to obtain well-crystallized HNPs with ordered nanostructured morphologies remains a great challenge.

As mentioned previously, ordered nanostructured HNP morphologies are prepared in various shapes. Notably, HNPs with spherical shapes are regarded as the optimized morphology for high packing density, balanced electron distribution, and charge migration due to its ideal surface-to-volume ratio, which promises good catalytic activity. The intrinsic properties of spherical nanostructured particles can also be fine-tuned by changing certain parameters such as diameter, bulk structure, surface chemistry, chemical composition, and crystallinity, which have led to continuous research interests [21]. Nevertheless, the currently available method for the synthesis of HNPs with a spherical morphology using pluronic surfactant shows that the nanostructure is easily disrupted, leading to the presence of mixed phases such as magnetite, wustite, and hematite with a sharp decrease in Barrett-Emmett-Teller (BET) surface area [22,23]. Evidently, it is challenging to retain spherical-shaped HNPs using the conventional surfactant-templated preparation methods. Therefore, the search for an environmentally friendly route, simple approach, and cost-effective method to prepare stable HNPs with spherical nanostructures for large-scale applications, particularly as a catalyst, is urgently required. To the best of our knowledge, the synthesis of spherical nanostructured HNPs using a native biomaterials template of rice starch without any additives in an aqueous solution has not been reported yet. In continuation of our work on the green synthesis of nanomaterials using rice starch [24], here, we report an additive-free method of rice starch-assisted synthesis for the fabrication of HNPs having a spherical morphology and a size of less than $50 \mathrm{~nm}$. Owing to the spherical shape and porous networks that led to a larger surface area, the HNPs synthesized from this method were successfully utilized as a catalyst for the degradation of methylene blue, a dye contaminant. 


\section{Materials and Methods}

\subsection{Preparation of Spherical Nanostructured Hematite (Sp-HNP)}

All the starting materials were analytical grade and used as received (i.e., without further purification). Rice starch (RS) of $99.9 \%$ purity (with $\sim 30 \%$ of amylose and $\sim 70 \%$ of amylopectin content) was purchased from Euramco (M) Ptd Ltd., Johor, Malaysia. Methylene blue (MB), ethanol, and hydrochloric acid ( $\mathrm{HCl})$ were purchased from MERCK (M) Sdn Bhd, Bandar Sunway, Selangor, Malaysia, and acetone was purchased from HmbG Chemical, Ludolfstr., Hamburg, Germany. Iron(II) sulphate heptahydrate $\left(\mathrm{FeSO}_{4} \cdot 7 \mathrm{H}_{2} \mathrm{O}, 99.9 \%\right)$ was purchased from Sigma-Aldrich (M) Sdn Bhd, Subang Jaya, Selangor, Malaysia. In a typical RS-assisted synthesis, the HNPs were synthesized according to a calculated molar composition of $\mathrm{H}_{2} \mathrm{O} / \mathrm{RS} / \mathrm{FeSO}_{4} \cdot 7 \mathrm{H}_{2} \mathrm{O}$ at 1:1:4. Firstly, an appropriate amount of $\mathrm{FeSO}_{4} \cdot 7 \mathrm{H}_{2} \mathrm{O}$ and $\mathrm{RS}$ were added to double distilled water $(<\mathrm{pH}=7)$, heated to $70{ }^{\circ} \mathrm{C}$, and constantly stirred for $1 \mathrm{~h}$. Then, the mixture was left at room temperature before being filtered, washed with double distilled water, and dried in oven at $100^{\circ} \mathrm{C}$ overnight to produce a dark paste. Henceforth, the dark paste is denoted as RS-HNP. Subsequently, the RS-HNP was heated to $700{ }^{\circ} \mathrm{C}$ (heating rate of $5{ }^{\circ} \mathrm{C} / \mathrm{min}$ ) in air at $1 \mathrm{~atm}$ and maintained at that temperature for $4 \mathrm{~h}$, before slowly being cooled to room temperature. For the complete removal of organic residue, the powder was treated with concentrated $\mathrm{HCl}(37 \% \mathrm{w} / \mathrm{w})$ for $1 \mathrm{~h}$ at room temperature before the samples were finally dried and collected as a reddish-brown powder, which is referred to as Sp-HNP.

\subsection{Characterization}

A Fourier-transform infrared (FTIR) spectrometer (Perkin-Elmer, Spectrum One, Waltham, MA, USA) was used to determine the vibrational wavenumber of the functional groups in the range from 4000 to $450 \mathrm{~cm}^{-1}$. The nitrogen adsorption-desorption measurement was performed using an AUTOSORB-1 Quantachrome volumetric adsorption analyzer (Boynton Beach, FL, USA) with nitrogen as the adsorbate at $77.35 \mathrm{~K}$ for full-scale adsorption-desorption isotherms. The samples were degassed at $363 \mathrm{~K}$ for $3 \mathrm{~h}$ and held at $433 \mathrm{~K}$ for $12 \mathrm{~h}$ before analysis. The specific surface area was calculated using a Barrett-Emmett-Teller (BET) model. Additionally, a Barrett-Joyner-Halenda $(\mathrm{BJH})$ model was used to calculate the pore volume distribution and the average pore size. X-ray diffraction (XRD) was carried out using a Bruker Advance D8 X-ray powder diffractometer (Karlsruhe, Germany) with $\mathrm{Cu} K \alpha$ radiation $(\lambda=1.54 \AA, \mathrm{kV}=40, \mathrm{~mA}=40)$. The morphology of the particles was observed using field emission scanning electron microscopy (FESEM, JSM-6700F, JEOL, Tokyo, Japan), attached with energy dispersive X-ray spectroscopy (FESEM-EDX), operated at $3.0 \mathrm{kV}$ to determine the elemental composition of the samples. The sample was pre-coated with platinum (Pt) at $10^{-1} \mathrm{mbar}$ using a Bio-Rad SEM system. Transmission electron microscopy (TEM) micrographs of the samples were recorded by a JEM-2100F Electron Microscope (JEOL, Tokyo, Japan) at $160 \mathrm{kV}$ accelerated voltage. The samples were ultrasonically dispersed in acetone and trapped on holey carbon membranes. The thermogravimetric analysis (TGA) of the RS-HNP sample was carried out using a Mettler Toledo TGA-SDTA 851e thermal analyzer (Columbus, OH, USA), with a heating rate of $10{ }^{\circ} \mathrm{C} \mathrm{min}^{-1}$ from room temperature to $1200{ }^{\circ} \mathrm{C}$ under a nitrogen atmosphere. For solid samples, the UV-Vis diffuse reflectance spectra (DR UV-Vis) were measured by a Perkin Elmer Lambda 900 ultraviolet-visible/near-infrared (UV-Vis/NIR, Waltham, MA, USA) using a polytetrafluoroethylene polymer as a standard background, scanning in the wavelength ranges from 250 to $900 \mathrm{~nm}$ against absorbance. For liquid samples, the UV-Vis spectra were measured using a Thermo Scientific GENESYS 10S (Madison, WI, USA) from 500 to $800 \mathrm{~nm}$.

\subsection{Catalytic Activity}

Methylene blue (MB), with the chemical formula of $\mathrm{C}_{16} \mathrm{H}_{18} \mathrm{ClN}_{3} \mathrm{~S}$, is a thiazine dye commonly used in the textile and printing industries [25]. Based on the structural analysis in Figure S1, the MB molecules consist of thiazines with a heterocyclic center attached to 2 aromatics molecules that provide 
extra stability and hinder its degradation under visible light. Its industrial effluents are harmful to living organisms and are a major source of water contamination, which is caused by the blocking of sunlight that, in turn, decreases the dissolved oxygen capacity. In humans, MB leads to vomiting, nausea, and permanent damages to eyes on acute exposure [26]. Therefore, the treatment of water effluents containing $\mathrm{MB}$ is one of the dire concerns in the field of environmental chemistry. In this study, MB was selected as a model of organic water contaminants to confirm the catalytic degradation activity of the synthesized Sp-HNP. In these experiments, $2.0 \mathrm{~mL}$ of $0.1 \mathrm{mM} \mathrm{MB}$ was mixed with $1.0 \mathrm{~mL}$ of $\mathrm{H}_{2} \mathrm{O}_{2}(35 \% \mathrm{v} / \mathrm{v})$ in a quartz cuvette and stirred for $30 \mathrm{~min}$ in dark conditions to reach the adsorption-desorption equilibrium. Afterwards, $0.05 \mathrm{~g}$ of the Sp-HNP was added to the reaction mixture and constantly stirred. The sample was then irradiated with a UV hand lamp $(6 \mathrm{~W}, \lambda=365 \mathrm{~nm}$, intensity $=0.8 \mu \mathrm{W} \mathrm{cm}^{-2}$ ), set perpendicular at a distance of $2 \mathrm{~cm}$. The absorption spectra were recorded through time-dependent UV-Vis at 30-min intervals over the scanning wavelength from 200 to $600 \mathrm{~nm}$, at room temperature $\left(25 \pm 2{ }^{\circ} \mathrm{C}\right)$. The absorption band of $\mathrm{MB}$ was taken at $506 \mathrm{~nm}$, and the degradation percentage was calculated using the following equation:

$$
\text { Degradation }(\%)=\left[\left(C_{o}-C_{t}\right) /\left(C_{o}\right)\right] \times 100 \%
$$

where $C_{o}$ is the initial concentration and $C_{t}$ is the concentration at time $t$.

\section{Results and Discussion}

\subsection{Characterization of Spherical Hematite (Sp-HNP)}

To monitor the progress of the reaction, FTIR spectroscopy was used to identify the vibrational spectra corresponding to the functional groups of the RS powder, RS-HNP paste, and Sp-HNP, as shown in Figure 1. In Figure 1a, the vibrational band at $2927 \mathrm{~cm}^{-1}$ was assigned to C-H stretches, whereas the IR peaks for RS at 1079 and $1021 \mathrm{~cm}^{-1}$ were assigned to the anhydroglucose ring of the $\mathrm{O}-\mathrm{C}$ stretch. Moreover, there was a broad band due to the hydrogen-bonded hydroxyl groups $(\mathrm{O}-\mathrm{H})$ at around $3400 \mathrm{~cm}^{-1}$, attributed to vibrational stretches of free, intermolecular-, and intramolecular-bound hydroxyl groups [27]. The vibrational bands at 1154, 1079, 1021 and $930 \mathrm{~cm}^{-1}$, were attributed to $\mathrm{C}-\mathrm{O}$ stretching in the fingerprint region [28,29]. Other vibrational bands in the fingerprint region, at 526,575, 609, 700 and $764 \mathrm{~cm}^{-1}$, were due to the skeletal mode vibrations of the pyranose ring in the glucose unit [27-29]. Intrinsically, based on the FTIR spectra in Figure 1a, the RS showed vibrational bands of an intact glucose polymer. In the case of the RS-HNP, the FTIR spectra were measured in Figure 1b. It can be observed that the salt precursor regulated by the RS polymer with the presence of Fe-ions' adsorption from the peak around $1032 \mathrm{~cm}^{-1}$, was due to the $\mathrm{C}-\mathrm{OH}$ bending and vibration of $\mathrm{C}-\mathrm{O}$ stretching $[10,20,28]$. In addition, the $\mathrm{COOH}$ asymmetric and symmetric stretching bands, which were found around 1623 and $1406 \mathrm{~cm}^{-1}$, also supported the presence of Fe-ions-starch [10]. It is suggested that the adsorption of the hematite on the RS involved the interactions with the $\mathrm{O}-\mathrm{H}$ group attributed to the stretching band at $3420 \mathrm{~cm}^{-1}$. The adsorption characteristic of the -FeOOH intermediates was not found at around $905 \mathrm{~cm}^{-1}$ due to its low concentration in the mixture of the RS-HNP. It can, therefore, be inferred from Figure $1 \mathrm{~b}$ that the Fe-ions were absorbed onto the RS polymer through physical interactions and chemical adsorptions from the existence of van der Waals forces [30]. Figure 1c shows the FTIR spectra for the Sp-HNP with strong vibrational bands at 594 and $474 \mathrm{~cm}^{-1}$, which were attributed to the hematite, $\alpha-\mathrm{Fe}_{2} \mathrm{O}_{3}[10,20]$. Judging from the intensity of these two peaks, it can be asserted that band 594 was greater than $474 \mathrm{~cm}^{-1}$ at a 3:1 ratio, hence confirming the formation of $\alpha-\mathrm{Fe}_{2} \mathrm{O}_{3}$ [20]. Both the vibrational bands corresponded to the $\mathrm{Fe}-\mathrm{O}$ bond in the hematite. To clarify, the presence of very weak vibrational bands at 1640 and $3430 \mathrm{~cm}^{-1}$ signified the presence of water molecules adsorbed on $\alpha-\mathrm{Fe}_{2} \mathrm{O}_{3}$ due to the hygroscopic nature of the metal oxide [31]. 


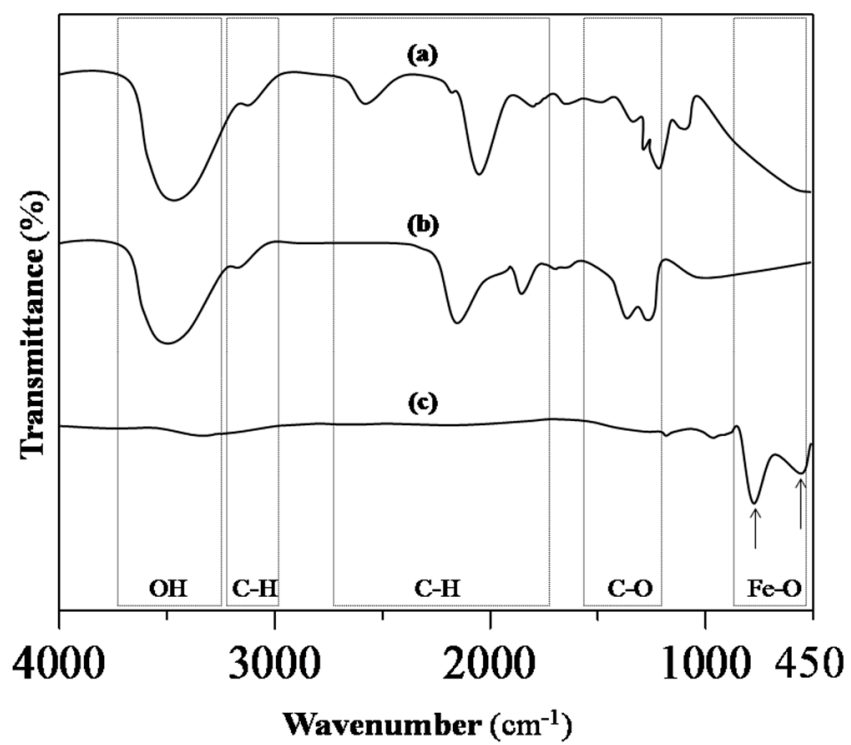

Figure 1. Fourier-transform infrared (FTIR) spectra of the (a) rice starch (RS); (b) RS-HNP, and (c) spherical nanostructured hematite (Sp-HNP).

In view of the crystallography, the RS and Sp-HNP were compared using XRD measurements, as shown in Figure 2. It is worth noting that starch is a semi-crystalline biopolymer, containing both amorphous and crystalline structures, with three different crystal types (A, B and C) according to their amylopectin packing [32]. The XRD diffractogram in Figure 2a showed observable peaks for the RS at $16^{\circ}, 17^{\circ}, 23^{\circ}$ and $24^{\circ}$. The broad and hardly distinguishable diffraction peaks suggested the presence of very small crystallite sizes. Based on the XRD pattern, the RS in its native granules exhibited a typical pattern of the type-A crystal structure [33]. In contrast, the XRD diffractogram for the Sp-HNP showed strong, narrow, sharp, and intense peaks, suggesting that the structures were well crystallized, as shown in Figure $2 \mathrm{~b}$. The major XRD peaks were measured at $24.14^{\circ}, 33.24^{\circ}, 35.61^{\circ}$, $40.81^{\circ}, 49.47^{\circ}, 54.09^{\circ}, 57.62^{\circ}, 62.46^{\circ}$ and $64.13^{\circ}$ and assigned to the $\left(\begin{array}{lll}0 & 1 & 2\end{array}\right),\left(\begin{array}{llll}1 & 0 & 4\end{array}\right),\left(\begin{array}{lll}1 & 1 & 0\end{array}\right),\left(\begin{array}{lll}1 & 1 & 3\end{array}\right)$, (0 2 4), (1 16 6), (0 18 8), (2 14 4), and (3 0 0) planes, respectively. The diffractogram was indexed to the theoretical data of the pure rhombohedral phase (a hexagonal crystal family) of the hematite (JCPDS card no.33-0664) $[10,34]$ and the lattice parameters: $a=b=0.501 \mathrm{~nm}, c=1.373 \mathrm{~nm}$. The powder pattern corresponded to $\alpha-\mathrm{Fe}_{2} \mathrm{O}_{3}$ with all the reflections of the similar peak width. The space group and spinel structure of the Sp-HNP was a R-3c, crystals system which was in good agreement with the literature [35]. Previously, the identical XRD pattern of the obtained $\alpha-\mathrm{Fe}_{2} \mathrm{O}_{3}$ was also reported by others $[10,36]$. From the XRD analysis, the highly crystalline Sp-HNP suggested that the particles were free from other impurity peaks such as b- $\mathrm{FeOOH}, \mathrm{Fe}_{3} \mathrm{O}_{4}$, or g- $\mathrm{Fe}_{2} \mathrm{O}_{3}$ [37]. The high purity indicated that the as-synthesized Sp-HNP is good for catalytic applications. Judging from the intense XRD peaks, it was evident that the Sp-HNP was pure, and the diffraction lines were considerably broadened due to the very small size of the hematite crystals.

Furthermore, the average particle sizes of the Sp-HNP can be calculated using the Debye-Scherrer equation. Briefly, it gives a relationship between the peak broadening in the XRD and the particle size according to the following equation:

$$
d=\mathrm{k} \lambda /(\beta \times \cos \theta)
$$

where $d$ is the particle size of the crystal, $\mathrm{k}$ is the Scherrer constant for the shape factor ( 0.9 was used for common crystallites), $\lambda$ is the $X$-ray wavelength used ( $\mathrm{Cu} \mathrm{K} \alpha=0.15406 \mathrm{~nm}), \beta$ is the full width at the half-height maxima (FWHM) of the concerned XRD peaks, and $\theta$ is the Bragg diffraction angle based on the determined incident grazing angle. The three most prominent peaks with Miller indices of (1 044$)$, (1 110$)$, and (1 116$)$ were considered for the estimation of the average crystallite size against $\mathrm{Si}\left(\begin{array}{lll}1 & 1 & 1\end{array}\right)$ FWHM for the reflection $\left(2 \theta=28.44^{\circ}\right.$ with $\mathrm{CuK} \alpha$ radiation $)$ of $2 \theta=0.10^{\circ}$ as standard. The measured 
$2 \theta$ values for the peaks of the $\operatorname{Si}\left(\begin{array}{lll}1 & 1 & 1\end{array}\right)$ standard materials pattern was in good agreement with the literature values [38]. Using the Debye-Scherrer, Equation (2), the average crystallite sizes of the Sp-HNP were calculated to be in the range of $26-40 \mathrm{~nm}$.

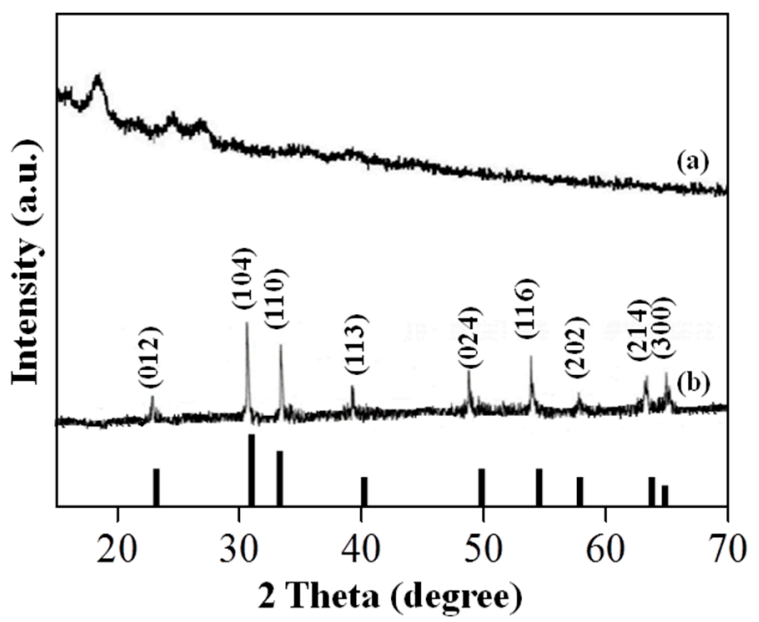

Figure 2. X-ray diffraction (XRD) patterns of the (a) RS and (b) Sp-HNP, indexed to the rhombohedral structure of hematite JCPDS card No. 33-0664 (vertical lines).

The representative thermogravimetric-differential thermal analysis (TGA-DTA) thermogram of the RS-HNP is shown in Figure 3. To confirm if the RS-HNP had completely converted into the Sp-HNP, the differential thermal analysis (DTA) thermogram revealed heat variations associated with different endothermic reactions. For the RS-HNP, the mass loss occurred in three steps following the endothermic reactions. Based on the thermogram, the initial weight loss of $2.8 \%$ at $110{ }^{\circ} \mathrm{C}$ was due to the removal of the adsorbed moisture and other volatile solvents in the RS-HNP. In the second step, a weight loss of $13.8 \%$ at $200{ }^{\circ} \mathrm{C}$ was measured, indicating the decomposition of an organic component of the polymeric RS in the RS-HNP. The final weight loss of $18.1 \%$ after $250{ }^{\circ} \mathrm{C}$ corresponded to the removal of the adsorbed oxygen species trapped in the nanoparticles [39]. The final residual mass was found to be $64.7 \%$, which corroborated the presence of $\alpha-\mathrm{Fe}_{2} \mathrm{O}_{3}$ for the Sp-HNP.

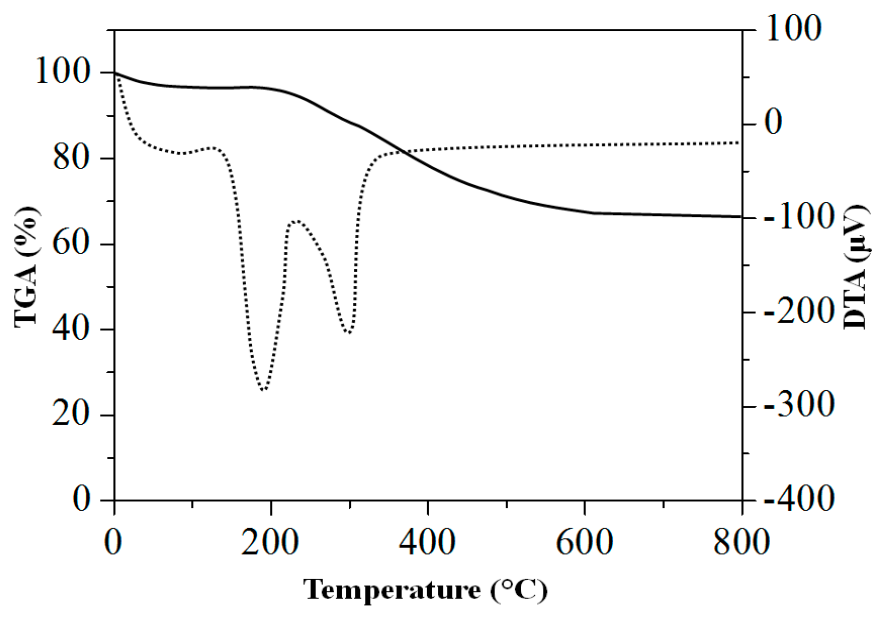

Figure 3. Thermogravimetric-differential thermal analysis (TGA-DTA) thermogram of the RS-HNP.

Figure 4a,b show the FESEM micrograph for the Sp-HNP, having a spherical morphology, at different magnifications. As suggested in the micrograph images, the Sp-HNP revealed almost monodispersed spherical-shaped nanoparticles. Based on the morphological analysis, the spherical shape of the Sp-HNP was also supported by ImageJ software (version 1.52e, ImageJ2, University of 
Wisconsin-Madison, WI, USA), as shown in Figure S2. Precisely, the hematite particles were found to nucleate and grow in a uniform direction. The steady growth of the hematite was consistent, which eventually developed well-ordered crystallites nanoparticles and the ordered spherical structure of the Sp-HNP. However, a small agglomeration that affected the Sp-HNP dispersity was deemed present. The composition of the particles was confirmed by the energy dispersive X-ray spectrum (EDX) as shown in Figure 4c. The EDX spectrum of the Sp-HNP indicated that there were only Fe (at 6.5 and $0.7 \mathrm{keV}$ ) and $\mathrm{O}$ (at $0.2 \mathrm{keV}$ ) measured in the samples due to the surface plasmon resonance [40]. This indicated that highly purified $\mathrm{Fe}_{2} \mathrm{O}_{3}$ nanoparticles were prepared by using the RS as a green template. It is worth mentioning that the peaks around $6.5 \mathrm{keV}$ were measured for the binding energies of $\mathrm{Fe}^{3+}$ related to the as-synthesized RS- $\mathrm{Fe}_{2} \mathrm{O}_{3}$ colloids [13,41]. As mentioned in the characterization, the Pt element measured at $2.2 \mathrm{keV}$ in the EDX was due to the pre-coating of the sample. As shown in Figure 4d, the Sp-HNP was distributed as spherical nanoparticles with diameters ranging in sizes of 24-48 $\mathrm{nm}$ and appeared to be well substantiated with the estimated value of the XRD. Table 1 represents the EDX depth analysis data obtained from selected area in Figure 4 b. In Table 1, the elemental composition for the Sp-HNP was confirmed to be Fe (at 35.89\%) and $\mathrm{O}$ (at $58.27 \%$ ), with no other impurities being detected. The calculated atomic ratio of Fe/O was about 1:1.62 $\left(\mathrm{Fe}_{2} \mathrm{O}_{3.25}\right)$, which agreed well with the expected stoichiometry $\left(\mathrm{Fe}_{2} \mathrm{O}_{3}\right)$. It should be noted that the EDX depth analysis measured several microns in depth from the surface of many HNPs, which might contribute to the experimental uncertainty.

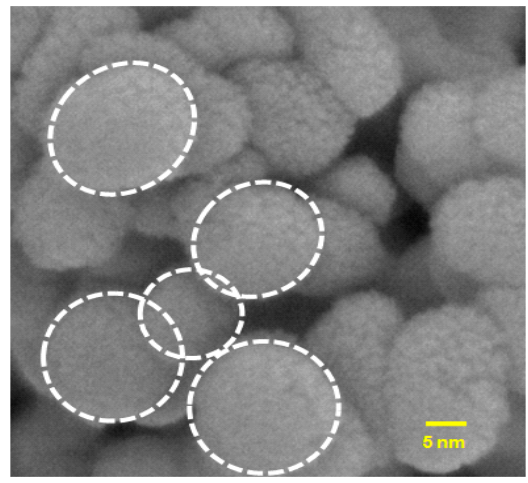

(a)

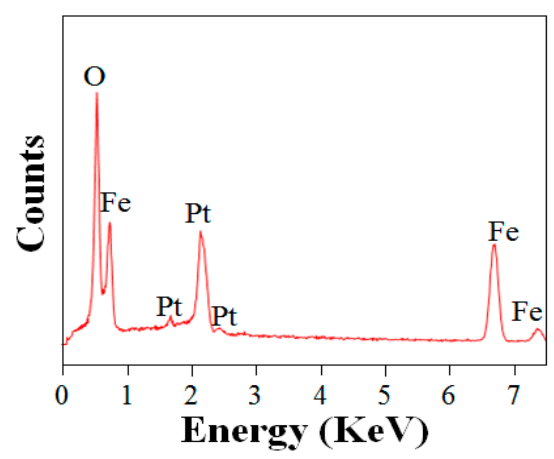

(c)

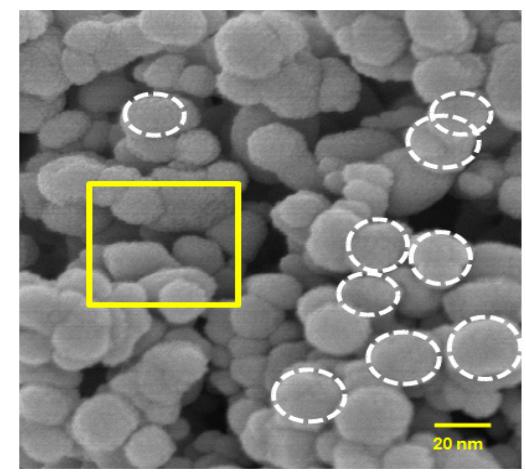

(b)

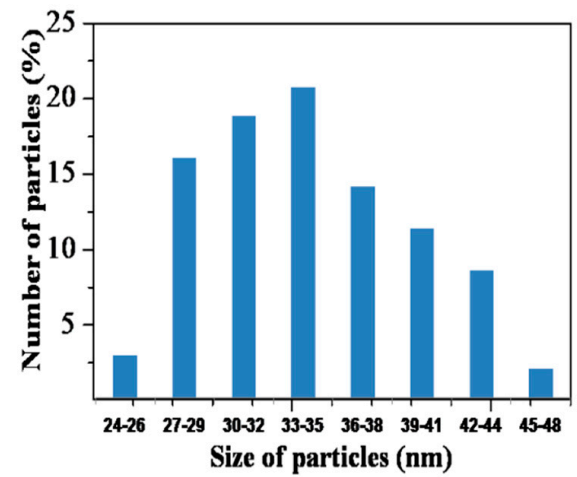

(d)

Figure 4. (a) Field emission scanning electron microscopy (FESEM) micrograph of the Sp-HNP at 20,000 $\times$ magnification (the dotted circle suggesting a spherical structure); (b) FESEM micrograph of the Sp-HNP at 5000 $\times$ magnification (with corresponding selected-area electron diffraction (SAED)); (c) energy dispersive $X$-ray spectroscopy (EDX) analysis spectra on SAED; and (d) histograms showing the particle size distributions. 
Table 1. EDX analysis for the spherical hematite (Sp-HNP) with Pt coating.

\begin{tabular}{cc}
\hline Elements & Atomic Percentage \\
\hline Platinum $(\mathrm{Pt})$ & 5.47 \\
Oxygen $(\mathrm{O})$ & 58.27 \\
Iron $(\mathrm{Fe})$ & 35.89 \\
\hline
\end{tabular}

The TEM micrograph images for the Sp-HNP in Figure 5 confirmed that the spherical nanostructures interlinked over a rhombohedral material [42] to give ordered shape and different sized particles of less than $50 \mathrm{~nm}$. These results strongly supported both the FESEM and XRD measurements. Figure 5 a reveals that the nanostructured Sp-HNP was composed of many tiny nanoparticles, with sizes around $20 \mathrm{~nm}$, which self-assembled into regular spheres, which might lead to the formation of a cavity or pores. The regular lattice fringes can be clearly seen in Figure 5b. Based on Figure 5b, the measured interplanar distance or lattice spacing in the TEM image was $0.25 \mathrm{~nm}$, which corresponds to the (1 10 ) plane of the hexagonal phase of $\mathrm{Fe}_{2} \mathrm{O}_{3}$, matching well with the XRD pattern for $\mathrm{d}_{110}$ spacing $\left(2 \theta=35.61^{\circ}\right)$ of the pure hexagonal hematite. The fast Fourier-transform (FFT) pattern (the inset) of the selected-area electron diffraction (SAED) in Figure 5a indicated the crystalline nature of the Sp-HNP. From the results, it is also suggested that the nanoparticles grew as uniform monocrystals of $\alpha-\mathrm{Fe}_{2} \mathrm{O}_{3}$ without any coalescence effects on the nanoparticles after the removal of the RS by the hydrothermal treatment to obtain the ordered spherical nanostructure.

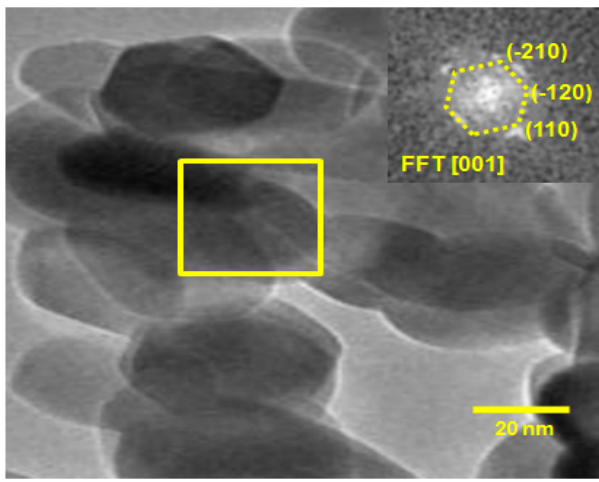

(a)

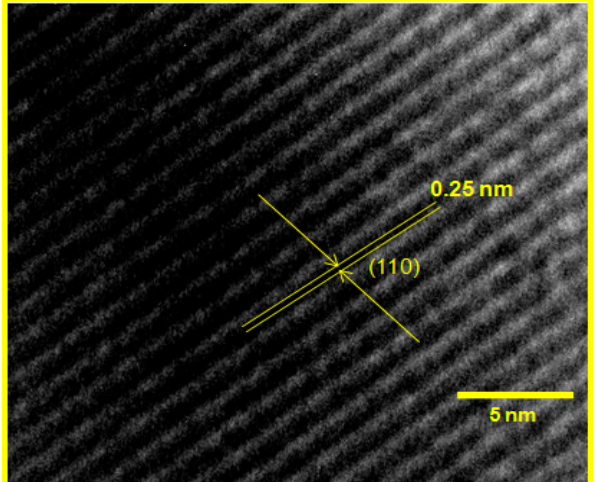

(b)

Figure 5. TEM micrograph of (a) hematite nanoparticles (HNPs), inset: corresponding fast Fourier-transform (FFT) pattern from the SAED and (b) lattice fringes at the $\left(\begin{array}{lll}1 & 1 & 0\end{array}\right)$ plane.

To quantify the surface area, the nitrogen $\left(\mathrm{N}_{2}\right)$ adsorption-desorption measurements and corresponding pore size distribution (PSD) obtained by the Barrett-Joyner-Halenda (BJH) method for the Sp-HNP are presented in Figure 6. Based on the measurements, the calculated Brunauer-EmmettTeller (BET) surface area was found to be $20.04 \mathrm{~m}^{2} / \mathrm{g}$. The obtained surface area for the Sp-HNP was relatively 20 times higher than most natural iron powders $\left(0.1-0.4 \mathrm{~m}^{2} / \mathrm{g}\right)$ and 4 times higher than the commercial hematite $\left(5 \mathrm{~m}^{2} / \mathrm{g}\right)$ [43]. Compared with other synthetic hematites, the surface area acquired from the starch-assisted synthesis was also considerably higher than that in the work presented by Park et al. (15.9 $\left.\mathrm{m}^{2} / \mathrm{g}\right)$ [23] and Wu et al. (15.8 $\left.\mathrm{m}^{2} / \mathrm{g}\right)$ [44]. According to the International Union of Pure and Applied Chemistry (IUPAC) classification, the $\mathrm{N}_{2}$ adsorption-desorption isotherms, as shown in Figure 6a, exhibited a typical type-IV isotherm with a H3-type hysteresis loop $\left(\mathrm{P} / \mathrm{P}_{0}>0.6\right)[45]$. The type-IV isotherm was caused by the capillary condensation in the mesopores networks of the Sp-HNP, while the H3-type hysteresis loop was attributed to slit-shaped pores. The results were consistent with those of other works producing HNPs from biomaterials templates [46,47]. As can be seen, the H3-type hysteresis loop appeared in the high-pressure region at a relative pressure 
higher than 0.6. This proposed the existence of voids, pores, or spaces in extra networks between the interconnected $\alpha-\mathrm{Fe}_{2} \mathrm{O}_{3}$ nanoparticles on the Sp-HNP [48]. It is worth mentioning that the controlled heat treatments and subsequent removal of the RS polymers enabled the synthesis of spatially separated $\alpha-\mathrm{Fe}_{2} \mathrm{O}_{3}$ nanoparticles. As shown in Figure $6 \mathrm{~b}$, the Sp-HNP showed PSD at 21-38 $\AA$ with predominant pore diameters at $22 \AA$. Notably, a broad peak centered at $29 \AA$ was attributed to secondary mesopores [44], which were contributed by the Sp-HNP agglomeration.

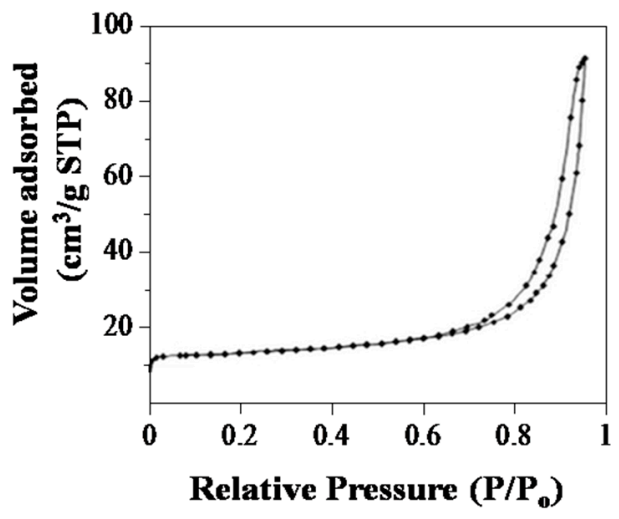

(a)

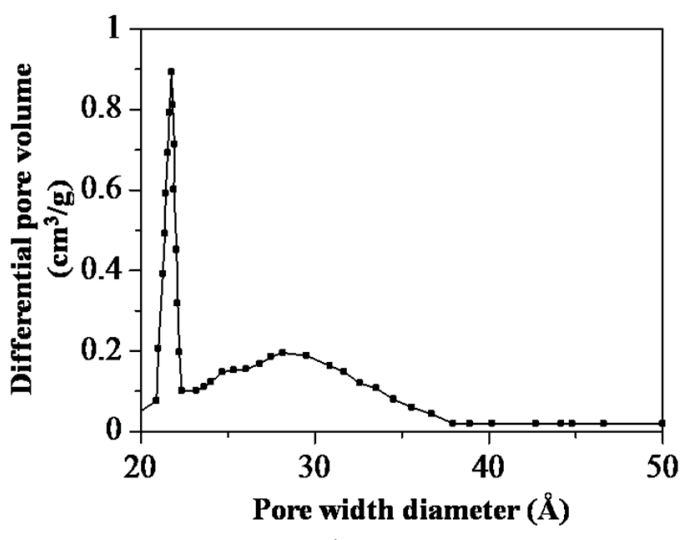

(b)

Figure 6. Nitrogen adsorption-desorption measurements (a) Isotherms plot; and (b) Barrett-JoynerHalenda (BJH) models.

The UV-Vis diffuse reflectance spectra of the RS and Sp-HNP samples are shown in Figure 7a. As can be seen, no significant absorption was obtained for the RS sample. Typically, the Sp-HNP gave four absorption regions spectra from (i) to (iv) detected in the UV-Visible spectral region (near-UV and near-infrared) contributed from the $\alpha-\mathrm{Fe}_{2} \mathrm{O}_{3}$ nanoparticles. In the same manner reported previously [43,49], the absorption at 250-400 nm corresponding to the ligand-to-metal charge transfer transitions (LMCT) was measured at region (i), attributed to the Fe-O $(\pi-3 \mathrm{~d})$ bond for somewhat from the $\mathrm{Fe}^{3+}$ ligand field transitions ${ }^{6} \mathrm{~A}_{1} \rightarrow{ }^{4} \mathrm{~T}_{1}\left({ }^{4} \mathrm{P}\right)$ at $290-310 \mathrm{~nm},{ }^{6} \mathrm{~A}_{1} \rightarrow{ }^{4} \mathrm{E}\left({ }^{4} \mathrm{D}\right)$ and ${ }^{6} \mathrm{~A}_{1} \rightarrow{ }^{4} \mathrm{~T}_{2}\left({ }^{4} \mathrm{D}\right)$ at 360-380 nm. For region (ii), the absorption from 400 to $600 \mathrm{~nm}$ was attributed to the pair excitation processes ${ }^{6} \mathrm{~A}_{1}+{ }^{6} \mathrm{~A}_{1} \rightarrow{ }^{4} \mathrm{~T}_{1}\left({ }^{4} \mathrm{G}\right)+{ }^{4} \mathrm{~T}_{1}\left({ }^{4} \mathrm{G}\right)$ at $485-550 \mathrm{~nm}$, partially overlapped ligand field transitions at $430 \mathrm{~nm}$ on of ${ }^{6} \mathrm{~A}_{1} \rightarrow{ }^{4} \mathrm{E},{ }^{4} \mathrm{~A}_{1}\left({ }^{4} \mathrm{G}\right)$, and charge-transfer (CT) shoulder. The absorption at $600-750 \mathrm{~nm}$ for region (iii) was assigned to the ${ }^{6} \mathrm{~A}_{1} \rightarrow{ }^{4} \mathrm{~T}_{2}\left({ }^{4} \mathrm{G}\right)$ transition at about $640 \mathrm{~nm}$. Lastly, region (iv) measured from 750 to $900 \mathrm{~nm}$ was the ${ }^{6} \mathrm{~A}_{1} \rightarrow{ }^{4} \mathrm{~T}_{1}\left({ }^{4} \mathrm{G}\right)$ transition at about $900 \mathrm{~nm}$. Both regions (iii) and (iv) were measured for an absorption peak around 500-900 nm, which could be deduced from the Fe-Fe bond on d-to-d transitions [50]. Based on selection rules [49,50], the absorption from the charge-transfer transitions in regions (i) and (ii) was stronger than that from the ligand field transitions in regions (iii) and (iv), as indicated from the UV-Vis absorption intensity $[43,49,50]$. More importantly, the bandgap $\left(E_{g}\right)$ value can be estimated using a Tauc Mott plot, by plotting $(\alpha h v)^{2}$ versus hv, as shown in Figure $7 b$. To obtain the desired bandgap, the Tauc's region was extrapolated to $(\alpha h v)^{2}=0$. The relationship between the absorption coefficient $(\alpha h v)^{n}$ and incident photon hv is shown based on the Tauc formula as follows:

$$
\alpha \mathrm{hv}=\mathrm{A}\left(\mathrm{h} v-\mathrm{E}_{\mathrm{g}}\right)^{n}
$$

where $\alpha$ is the absorption coefficient, hv is the photon energy, $\mathrm{A}$ is constant, $\mathrm{n}$ can be 2 (indirect transition) or $1 / 2$ (direct transition), and $\mathrm{E}_{\mathrm{g}}$ is the allowed bandgap. As shown in Figure $7 \mathrm{~b}$, the indirect bandgap values were extrapolated at $2.38 \mathrm{eV}$. The obtained value was comparable to those synthesized $\alpha-\mathrm{Fe}_{2} \mathrm{O}_{3}$ nanoparticles that absorb visible light [51], suggesting that the Sp-HNP has a medium bandgap (at 1-3 eV) and promising semiconductor applications (i.e., as a photocatalyst) [52]. 


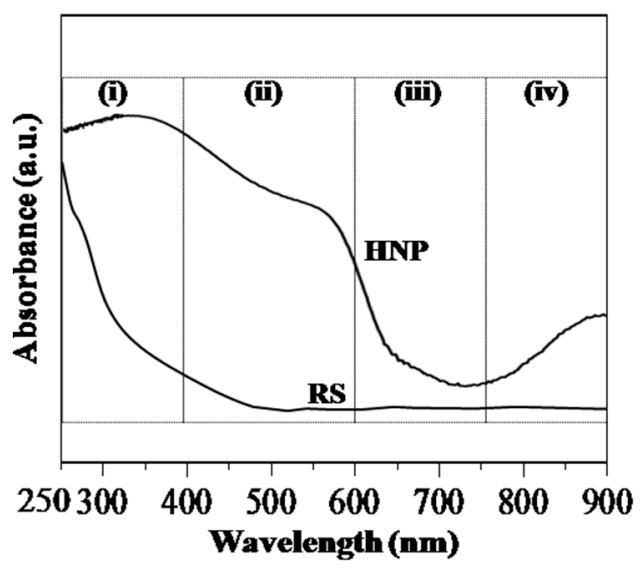

(a)

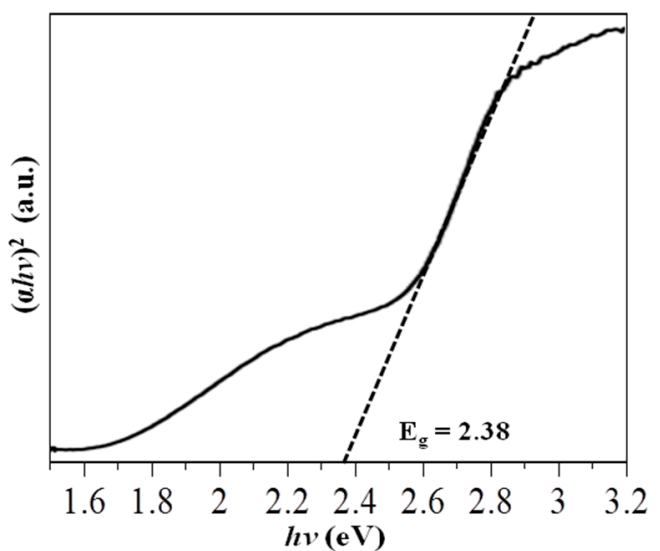

(b)

Figure 7. Optical analysis for (a) UV-Vis diffuse reflectance spectroscopy (DR UV-Vis) and (b) Tauc plot of the Sp-HNP.

\subsection{Plausible Formation of Spherical Hematite (Sp-HNP)}

Based on the characterization of the Sp-HNP, a schematic formation could be depicted in Figure 8. The highlighted additive-free procedure was mainly due to the multifunctional RS that can act as both reducing and capping agents (stabilizer) simultaneously. During the synthesis, the iron(II) sulfate powder initially converted into Fe-ions of metal aquo complex $\left[\mathrm{Fe}\left(\mathrm{H}_{2} \mathrm{O}\right)_{6}\right]^{2+}$ upon dissolving in water. Notably, RS consists of linear amylose and branched amylopectin structures, is rich with hydroxyl $(\mathrm{OH})$ backbones, and contains abundant alcohol terminals $(\mathrm{COH})$, as shown in Figure S3. The OH backbones reasonably facilitated the complexation of Fe-ions to the RS polymer, while the alcohol terminals assisted in the reduction of the Fe-ions (+2) to Fe (0) nanoparticles [53]. Taking starch retrogradation process [54] into consideration, the retrograded RS became soluble in hot water, indicating that the polysaccharides granules swelled and burst, destroying the rigidity of the semi-crystalline structure as the smaller amylose started leaching out and leaving behind the amylopectin in the granules. It can, therefore, be inferred that after adding the iron(II) sulfate solution to the RS solution, the Fe-ions were attracted by the oxygen of the $\mathrm{OH}$ branches, selectively on the polysaccharides backbone at $70{ }^{\circ} \mathrm{C}$, seeding inside the granules regions of high concentrations of amylopectin. The smaller amylose molecules began to form a gelatinized network on continuous heating outside the granules, which increased the mixture's viscosity (Scheme 1 in Figure 8). At the same time, the long-chain amylopectin assisted in the nucleation and promoted the initial growth of the hematite crystallites inside the granules, as well as controlling the self-assembly into nano-spherical morphology. For the most part, the van der Waals interactions between the surface molecules of the hematite crystallites (RS-metal ion interactions) are recognized as the driving force for self-assembly, favoring the formation of larger Sp-HNPs spheres due to extensive self-assembled nanocrystals. The formation of the RS-HNP paste indicates the synthesis of starch-stabilized nanoparticles that is similar to other reports for $\mathrm{ZnO}$, $\mathrm{Ag}$, and Au nanoparticles [55-57]. In the case of the RS-HNP, the long alkyl chain of RS resulted in stable homogeneous nanoparticles and prevented agglomeration (Scheme 2 in Figure 8). When further heated, the RS-HNP yielded the crystallized Sp-HNP (Scheme 3 in Figure 8) and byproducts of sulfur dioxide, $\mathrm{SO}_{2}$, and sulfur trioxide, $\mathrm{SO}_{3}$, according to the following chemical equation:

$$
2 \mathrm{FeSO}_{4} \rightarrow \mathrm{Fe}_{2} \mathrm{O}_{3}+\mathrm{SO}_{2}+\mathrm{SO}_{3}
$$

As for the role of RS, it did not only function in reducing and stabilizing the Sp-HNP to protect it from the sintering effect and agglomeration, but it also can be suggested as the nanostructured template to control the morphology, as well as the nanoparticles' sizes. Intriguingly, the obtained 
Sp-HNP showed a high-quality hematite, giving a clean spectrum in FTIR, intense XRD diffractogram peaks, and highly ordered nanoparticles in TEM, respectively (Figures 2, 3 and 5). In addition, the biomaterial features of RS have several advantages to its use in a green-synthesis method. First, the environmentally friendly approach from the dispersion of Fe-ions-RS in $\mathrm{H}_{2} \mathrm{O}$ to give the RS-HNP implies benign reagents from biomaterials without the need of organic solvents. Second, the interaction of the van der Waals forces between Fe-ions-RS is relatively weak as compared with the interaction by the hydrogen bond from the typical thiol-based additives [58]. The weak interaction enabled complete removal of the organic component from the metals to produce highly ordered HNPs, as supported by FTIR, TGA, XRD, FESEM-EDX, and TEM analysis. It is of interest that the Sp-HNP showed a magnetic response when applied with an external magnet, as shown in Figure S4. This promises a prospect for easy separation, hence increasing its reusability purpose. Previous work has shown that HNPs have been separated using an external magnet from their reacting mixtures and reused to demonstrate their functional stability [59]. The specific $\alpha-\mathrm{Fe}_{2} \mathrm{O}_{3}$, having rhombohedral repeating units with a hexagonal centered structure and close-packed oxygen in the nano-sized array, allowed the magnetic response [60].

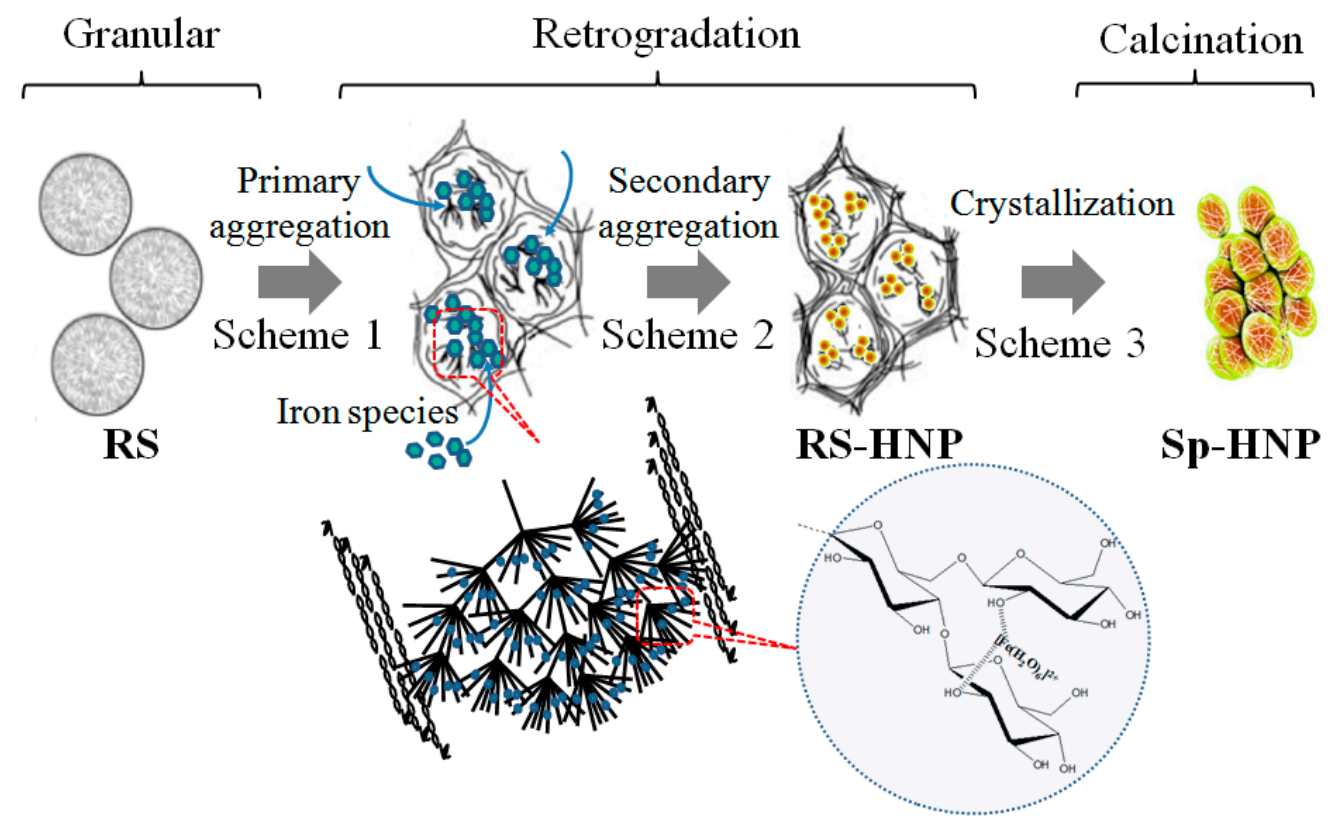

Figure 8. Schematic formation of the Sp-HNP through RS-assisted synthesis.

\subsection{Catalytic Activity}

Although the focus of the study is the RS assisted-synthesis of the Sp-HNP for nanostructured hematites, the application of the Sp-HNP as a photocatalyst represents a further remarkable feature. The Sp-HNP was expected to demonstrate promising catalytic capability, especially when the spherical morphology can facilitate the optimum charge migration without any diffusion limitations of reactant molecules due to porous networks. As reported by Singh and his co-workers, IONPs were used in the removal of toxic ions and organic pollutants due to the presence of porous networks [61]. In this study, the Sp-HNP underwent a catalytic performance evaluation by comparing the absorption spectra of the degraded MB, which was irradiated under UV light within certain periods. Figure 9 shows the performance of the prepared catalysts, examined by the degradation of MB for 270 min. From Figure $9 b$, MB was measured to degrade at $17 \%$ upon adding $\mathrm{H}_{2} \mathrm{O}_{2}$ exposed under UV light irradiation after $30 \mathrm{~min}$. After a period of time, MB further degraded to 50\% and 99\%, monitored after 120 and $270 \mathrm{~min}$, respectively. The degradation process was also supported by the photo-captured images in Figure S5a. It is worth mentioning that MB was not significantly degraded in dark conditions, indicating 
dependency on the UV light. Importantly, the process was chemical photo-degradation rather than physical adsorption. For comparison, the MB degradation experiment was also performed in presence of $\mathrm{H}_{2} \mathrm{O}_{2}$ and/or the UV light without the Sp-HNP (Figure S5). It can be seen that the degradation of MB is hardly initiated without the Sp-HNP, which confirms its catalytic activity. Nonetheless, the catalytic activity of the Sp-HNP is comparable to that of the previously reported HNPs as a catalyst [62].

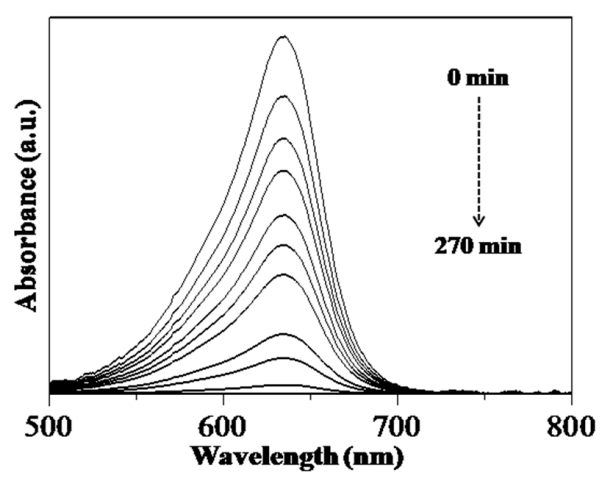

(a)

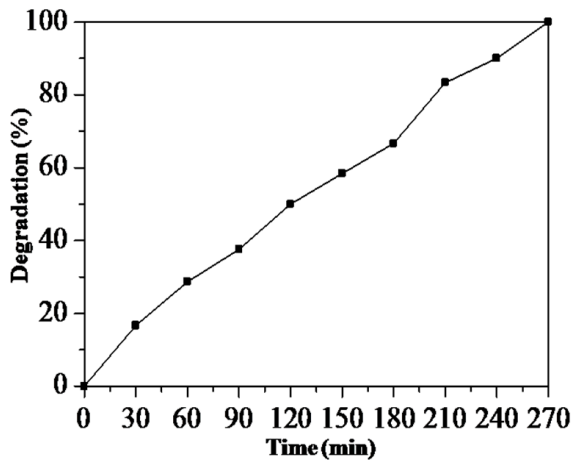

(b)

Figure 9. Degradation of methylene blue (MB) for 270 min under (a) UV-Vis and (b) plot of degradation (\%) against time.

As shown in Figure 10, the rate of the photocatalytic degradation of MB was deduced from the plot of the concentration against the irradiation time for $180 \mathrm{~min}$. The overall $\mathrm{MB}$ degradation showed both an exponential and linear relationship of pseudo-first-order kinetics, as indicated in the inset of Figure 10 for the full degradation time up to $270 \mathrm{~min}$. For all the initial concentrations of MB, the degradation gave a straight line that fits well into a logarithmic function, as commonly observed in the photocatalytic degradation reactions of most organic compounds [63]. Hence, the kinetic study on the rate of the degradation for $\mathrm{MB}$ in the presence of the Sp-HNP followed the pseudo-first-order reaction. The plot for line $\left(C_{t} / C_{0}\right)$ against time showed a linear relationship until $180 \mathrm{~min}$ of degradation time, so the rate constant $(\mathrm{k})$ can be determined from the gradient. Here, $\mathrm{C}_{0}$ and $\mathrm{C}_{t}$ are the initial concentration of $\mathrm{MB}$ and the concentration of $\mathrm{MB}$ after $t$, irradiation time, respectively. Moreover, the calculated $\mathrm{k}$ for the degradation reactions was $5.68 \times 10^{-3} \mathrm{~min}^{-1}$ and the half-life, the $t_{1 / 2}$ value, was found to be $122 \mathrm{~min}$, suggesting that the Sp-HNP causes good photo-degradation of $\mathrm{MB}$.

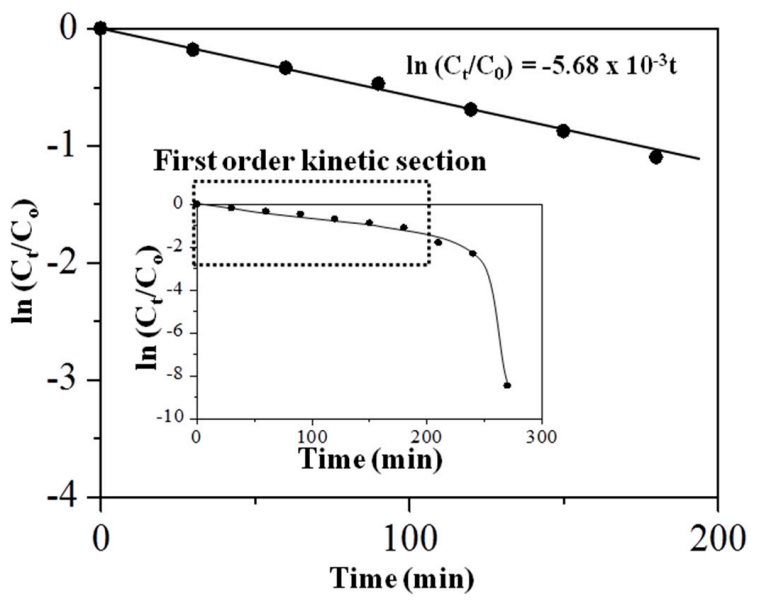

Figure 10. Concentration of $\mathrm{MB}$ as a function of the irradiation time for $180 \mathrm{~min}$. The inset shows the concentration of $\mathrm{MB}$ for the full irradiation time from 0 to $270 \mathrm{~min}$ with the first-order kinetic section defined in the dotted box. 


\section{Conclusions}

In conclusion, ordered nanoparticles and the monodispersed spherical iron oxide of Sp-HNP have been prepared by using an additive-free method, followed by controlled hydrothermal treatments. For the additive-free method, RS was successfully employed as a simple, environmentally friendly and low-cost multifunctional reducing and stabilizing agent. Briefly, the presence of RS protected the nucleation growth of the HNPs against sintering and agglomeration and allowed the avoidance of the use of unnecessary additives. The homogeneous nucleation process of Fe-ions happened during the retrogradation of the rice starch inside the granular networks to regulate the size and morphology of the Sp-HNP. Based on the physicochemical characterization, the synthesized Sp-HNP had a spherical-shaped, nano-sized morphology from 24 to $48 \mathrm{~nm}$, a pure rhombohedral crystalline structure, and a good surface area of $20.04 \mathrm{~m}^{2} / \mathrm{g}$, which is comparable to most conventional hematite nanoparticles. In addition, because the facile synthesis procedure does not require the introduction of any additives to the reaction system, this simple synthesis method has the potential to be suitable for the synthesis of other novel nanostructured metals. Based on its catalytic performance, the Sp-HNP successfully degraded MB at 99\% (after 270 min irradiation under UV light) and obeyed the pseudo-first-order kinetics. In the future, the RS-assisted synthesis presented here will ensure a marked improvement in the studies of advanced nanomaterials that demand spherical nanostructured hematite, especially with respect to size-dependent particles for magnetization properties in biomedical imaging, lithium batteries, and gas sensors.

Supplementary Materials: The following are available online at http:/ / www.mdpi.com/2079-4991/8/9/702/, Figure S1: Structural analysis (a) methylene blue (MB) with the chemical formula of C16H18CIN3S; and (b) ball and stick model based on Molecular Mechanics-2 (MM2) for MB at different perspectives showing a sterically hindered central portion of molecules. The presence of $\mathrm{Cl}-$ is omitted to avoid bulky structures. Figure S2: Morphological analysis for Sp-HNP showing the spherical morphology on a surface plot analyzed using ImageJ from Java-based software version 1.52e. Figure S3: Rice starch (RS) granules model representing linear amylose and branched amylopectin chains. Figure S4: Photo-captured image on Sp-HNP (reddish-brown powder), showing a magnetic response when applied with an external magnet. Figure S5: Catalytic activity for the degradation of MB (a) Photo-captured images for MB/Sp-HNP/H2O2/UV; Ultraviolet-visible (UV-Vis) spectra for different conditions: (b) MB/UV/H2O2; (c) MB/H2O2; and (d) MB/UV without the presence of the Sp-HNP catalyst

Author Contributions: J.M. and S.E. conceived of and designed the experiments; J.M. performed the experiments; J.M., I.A. and S.I.I. contributed reagents/materials/analysis tools; and J.M. and I.A. analyzed the data and wrote the paper. All authors have read and approved the final manuscript.

Funding: This work was financially supported by Universiti Teknologi Mara (UiTM, Malaysia) under research grant cost centre No. 600-UiTMSEL (PI. 5/4) (044/2018).

Acknowledgments: We highly appreciated the use of ImageJ software as our open source image processing program, obtained at https:/ / imagej.net/Downloads.

Conflicts of Interest: The authors declare no conflicts of interest.

\section{References}

1. Karagoz, B.; Yeow, J.; Esser, L.; Prakash, S.M.; Kuchel, R.P.; Davis, T.P.; Boyer, C. An Efficient and Highly Versatile Synthetic Route to Prepare Iron Oxide Nanoparticles/Nanocomposites with Tunable Morphologies. Langmuir 2014, 30, 10493-10502. [CrossRef] [PubMed]

2. Li, J.; Cushing, S.K.; Zheng, P.; Meng, F.; Chu, D.; Wu, N. Plasmon-Induced Photonic and Energy-Transfer Enhancement of Solar Water Splitting by a Hematite Nanorod Array. Nat. Commun. 2013, 4, 2651. [CrossRef] [PubMed]

3. Yang, Y.; Ma, H.; Zhuang, J.; Wang, X. Morphology-Controlled Synthesis of Hematite Nanocrystals and Their Facet Effects on Gas-Sensing Properties. Inorg. Chem. 2011, 50, 10143-10151. [CrossRef] [PubMed]

4. Ling, D.; Lee, N.; Hyeon, T. Chemical Synthesis and Assembly of Uniformly Sized Iron Oxide Nanoparticles for Medical Applications. Acc. Chem. Res. 2015, 48, 1276-1285. [CrossRef] [PubMed]

5. Wheeler, D.A.; Wang, G.; Ling, Y.; Li, Y.; Zhang, J.Z. Nanostructured Hematite: Synthesis, Characterization, Charge Carrier Dynamics and Photoelectrochemical Properties. Energy Environ. Sci. 2012, 5, 6682-6702. [CrossRef] 
6. Ali, A.; Hira Zafar, M.Z.; Ul Haq, I.; Phull, A.R.; Ali, J.S.; Hussain, A. Synthesis, Characterization, Applications, and Challenges of Iron Oxide Nanoparticles. Nanotechnol. Sci. Appl. 2016, 9, 49. [CrossRef] [PubMed]

7. Saif, S.; Tahir, A.; Chen, Y. Green Synthesis of Iron Nanoparticles and Their Environmental Applications and Implications. Nanomaterials 2016, 6, 209. [CrossRef] [PubMed]

8. Lu, A.H.; Salabas, E.E.; Schüth, F. Magnetic Nanoparticles: Synthesis, Protection, Functionalization, and Application. Angew. Chem. Int. Ed. 2007, 46, 1222-1244. [CrossRef] [PubMed]

9. Ozaki, M.; Suzuki, H.; Takahashi, K.; Matijević, E. Reversible Ordered Agglomeration of Hematite Particles due to Weak Magnetic Interactions. J. Colloid Interface Sci. 1986, 113, 76-80. [CrossRef]

10. Das, P.; Mondal, B.; Mukherjee, K. Facile Synthesis of Pseudo-Peanut Shaped Hematite Iron Oxide Nano-Particles and Their Promising Ethanol and Formaldehyde Sensing Characteristics. RSC Adv. 2014, 4, 31879-31886. [CrossRef]

11. Patra, A.K.; Kundu, S.K.; Bhaumik, A.; Kim, D. Morphology Evolution of Single-Crystalline Hematite Nanocrystals: Magnetically Recoverable Nanocatalysts for Enhanced Facet-Driven Photoredox Activity. Nanoscale 2016, 8, 365-377. [CrossRef] [PubMed]

12. Trpkov, D.; Panjan, M.; Kopanja, L.; Tadić, M. Hydrothermal Synthesis, Morphology, Magnetic Properties and Self-Assembly of Hierarchical $\alpha-\mathrm{Fe}_{2} \mathrm{O}_{3}$ (Hematite) Mushroom-, Cube-and Sphere-like Superstructures. Appl. Surf. Sci. 2018, 457, 427-438. [CrossRef]

13. Zhu, M.; Wang, Y.; Meng, D.; Qin, X.; Diao, G. Hydrothermal Synthesis of Hematite Nanoparticles and Their Electrochemical Properties. J. Phys. Chem. C 2012, 116, 16276-16285. [CrossRef]

14. Doermbach, K.; Pich, A. Facile Synthesis of Dumbbell-Shaped Multi-Compartment Nanoparticles. Nanoscale 2015, 7, 9169-9173. [CrossRef] [PubMed]

15. Aslam, M.; Schultz, E.A.; Sun, T.; Meade, T.; Dravid, V.P. Synthesis of Amine-Stabilized Aqueous Colloidal Iron Oxide Nanoparticles. Cryst. Growth Des. 2007, 7, 471-475. [CrossRef] [PubMed]

16. Hao, H.; Sun, D.; Xu, Y.; Liu, P.; Zhang, G.; Sun, Y.; Gao, D. Hematite Nanoplates: Controllable Synthesis, Gas Sensing, Photocatalytic and Magnetic Properties. J. Colloid Interface Sci. 2016, 462, 315-324. [CrossRef] [PubMed]

17. Asenath-Smith, E.; Estroff, L.A. Role of Akaganeite $(\beta-\mathrm{FeOOH})$ in the Growth of Hematite $\left(\alpha-\mathrm{Fe}_{2} \mathrm{O}_{3}\right)$ in an Inorganic Silica Hydrogel. Cryst. Growth Des. 2015, 15, 3388-3398. [CrossRef]

18. Gnanaprakash, G.; Mahadevan, S.; Jayakumar, T.; Kalyanasundaram, P.; Philip, J.; Raj, B. Effect of Initial pH and Temperature of Iron Salt Solutions on Formation of Magnetite Nanoparticles. Mater. Chem. Phys. 2007, 103, 168-175. [CrossRef]

19. Hao, T.; Yang, C.; Rao, X.; Wang, J.; Niu, C.; Su, X. Facile Additive-Free Synthesis of Iron Oxide Nanoparticles for Efficient Adsorptive Removal of Congo Red and Cr (VI). Appl. Surf. Sci. 2014, 292, 174-180. [CrossRef]

20. Janardhanan, S.K.; Ramasamy, I.; Nair, B.U. Synthesis of Iron Oxide Nanoparticles Using Chitosan and Starch Templates. Transit. Metal Chem. 2008, 33, 127-131. [CrossRef]

21. Kumar, S.V.; Bafana, A.P.; Pawar, P.; Rahman, A.; Dahoumane, S.A.; Jeffryes, C.S. High Conversion Synthesis of $<10 \mathrm{~nm}$ Starch-Stabilized Silver Nanoparticles Using Microwave Technology. Sci. Rep. 2018, 8, 5106. [CrossRef] [PubMed]

22. Lee, Y.C.; Lee, H.U.; Oh, S.Y.; Jang, S.C.; Lee, S.C.; Huh, Y.S. Self-Assembled/Oval-Shaped Iron Oxide Nanoparticles for Efficient Photo-Fenton Reaction at Neutral pH. J. Nanosci. Nanotechnol. 2017, 17, 7651-7655. [CrossRef]

23. Park, C.; Jung, J.; Lee, C.W.; Cho, J. Synthesis of Mesoporous $\alpha-\mathrm{Fe}_{2} \mathrm{O}_{3}$ Nanoparticles by Non-Ionic Soft Template and Their Applications to Heavy Oil Upgrading. Sci. Rep. 2016, 6, 39136. [CrossRef] [PubMed]

24. Matmin, J.; Affendi, I.; Endud, S. Direct-Continuous Preparation of Nanostructured Titania-Silica Using Surfactant-Free Non-Scaffold Rice Starch Template. Nanomaterials 2018, 8, 514. [CrossRef] [PubMed]

25. Rafatullah, M.; Sulaiman, O.; Hashim, R.; Ahmad, A. Adsorption of Methylene Blue on Low-Cost Adsorbents: A Review. J. Hazard. Mater. 2010, 177, 70-80. [CrossRef] [PubMed]

26. Lo, J.C.; Darracq, M.A.; Clark, R.F. A Review of Methylene Blue Treatment for Cardiovascular Collapse. J. Emerg. Med. 2014, 46, 670-679. [CrossRef] [PubMed]

27. Fang, J.M.; Fowler, P.A.; Sayers, C.; Williams, P.A. The Chemical Modification of a Range of Starches under Aqueous Reaction Conditions. Carbohydr. Polym. 2004, 55, 283-289. [CrossRef] 
28. Goheen, S.M.; Wool, R.P. Degradation of Polyethylene-Starch Blends in Soil. J. Appl. Polym. Sci. 1991, 42, 2691-2701. [CrossRef]

29. Kizil, R.; Irudayaraj, J.; Seetharaman, K. Characterization of Irradiated Starches by Using FT-Raman and FTIR Spectroscopy. J. Agric. Food Chem. 2002, 50, 3912-3918. [CrossRef] [PubMed]

30. Yue, T.; Wu, X. Depressing Iron Mineral by Metallic-Starch Complex (MSC) in Reverse Flotation and Its Mechanism. Minerals 2018, 8, 85. [CrossRef]

31. Justus, J.S.; Roy, S.D.D.; Raj, A.M.E. Synthesis and Characterization of Hematite Nanopowders. Mater. Res. Express 2016, 3, 105037. [CrossRef]

32. Wang, T.L.; Bogracheva, T.Y.; Hedley, C.L. Starch: As simple as A, B, C? J. Exp. Bot. 1998, 49, 481-502. [CrossRef]

33. Buléon, A.; Colonna, P.; Planchot, V.; Ball, S. Starch Granules: Structure and Biosynthesis. Int. J. Biol. Macromol. 1998, 23, 85-112. [CrossRef]

34. Chen, L.; Yang, X.; Chen, J.; Liu, J.; Wu, H.; Zhan, H.; Liang, C.; Wu, M. Continuous Shape-and Spectroscopy-Tuning of Hematite Nanocrystals. Inorg. Chem. 2010, 49, 8411-8420. [CrossRef] [PubMed]

35. Catti, M.; Valerio, G.; Dovesi, R. Theoretical Study of Electronic, Magnetic, and Structural Properties of $\alpha-\mathrm{Fe}_{2} \mathrm{O}_{3}$ (Hematite). Phys. Rev. B 1995, 51, 7441. [CrossRef]

36. Liu, C.; Ma, J.; Liu, Y. Formation Mechanism and Magnetic Properties of Three Different Hematite Nanostructures Synthesized by One-Step Hydrothermal Procedure. Sci. China Chem. 2011, 54, 1607. [CrossRef]

37. Chikate, R.C.; Jun, K.W.; Rode, C.V. Nonaqueous Synthesis and Characterization of Capped $\alpha$-Fe2O3 Nanoparticles from Iron (III) Hydroxy-Oleate Precursor. Polyhedron 2008, 27, 933-938. [CrossRef]

38. Zaumseil, P. X-ray Measurement of the Tetragonal Distortion of the Oxide Buffer Layer in $\mathrm{Ge}_{2} / \mathrm{Pr}_{2} \mathrm{O}_{3} / \mathrm{Si}$ (1 11 1) Heteroepitaxial Structures. J. Phys. D Appl. Phys. 2008, 41, 135308. [CrossRef]

39. Sayed, F.N.; Polshettiwar, V. Facile and Sustainable Synthesis of Shaped Iron Oxide Nanoparticles: Effect of Iron Precursor Salts on the Shapes of Iron Oxides. Sci. Rep. 2015, 5, 9733. [CrossRef] [PubMed]

40. Basavegowda, N.; Mishra, K.; Lee, Y.R. Synthesis, Characterization, and Catalytic Applications of Hematite $\left(\alpha-\mathrm{Fe}_{2} \mathrm{O}_{3}\right)$ Nanoparticles as Reusable Nanocatalyst. Adv. Nat. Sci. Nanosci. Nanotechnol. 2017, 8, 025017. [CrossRef]

41. Dutta, R.K.; Sahu, S. Development of Oxaliplatin Encapsulated in Magnetic Nanocarriers of Pectin as a Potential Targeted Drug Delivery for Cancer Therapy. Res. Pharm. Sci. 2012, 2, 38-45. [CrossRef] [PubMed]

42. Mohammadikish, M. Hydrothermal Synthesis, Characterization and Optical Properties of Ellipsoid Shape $\alpha$-Fe2O3 Nanocrystals. Ceram. Int. 2014, 40, 1351-1358. [CrossRef]

43. Ahmmad, B.; Leonard, K.; Islam, M.S.; Kurawaki, J.; Muruganandham, M.; Ohkubo, T.; Kuroda, Y. Green Synthesis of Mesoporous Hematite $\left(\alpha-\mathrm{Fe}_{2} \mathrm{O}_{3}\right)$ Nanoparticles and Their Photocatalytic Activity. Adv. Powder Technol. 2013, 24, 160-167. [CrossRef]

44. Wu, C.; Yin, P.; Zhu, X.; OuYang, C.; Xie, Y. Synthesis of Hematite $\left(\alpha-\mathrm{Fe}_{2} \mathrm{O}_{3}\right)$ Nanorods: Diameter-Size and Shape Effects on Their Applications in Magnetism, Lithium Ion Battery and Gas Sensors. J. Phys. Chem. B 2006, 110, 17806-17812. [CrossRef] [PubMed]

45. Sing, K.S.; Williams, R.T. Physisorption Hysteresis Loops and the Characterization of Nanoporous Materials. Adsorpt. Sci. Technol. 2004, 22, 773-782. [CrossRef]

46. Liu, S.; Tao, D.; Zhang, L. Cellulose Scaffold: A Green Template for the Controlling Synthesis of Magnetic Inorganic Nanoparticles. Powder Technol. 2012, 217, 502-509. [CrossRef]

47. Novoselova, L.Y. Hematite Nanopowder Obtained from Waste: Iron-Removal Sludge. Powder Technol. 2016, 287, 364-372. [CrossRef]

48. Zhou, W.; Lin, L.; Wang, W.; Zhang, L.; Wu, Q.; Li, J.; Guo, L. Hierarchial Mesoporous Hematite with "Electron-Transport Channels" and Its Improved Performances in Photocatalysis and Lithium Ion Batteries. J. Phys. Chem. C 2011, 115, 7126-7133. [CrossRef]

49. He, Y.P.; Miao, Y.M.; Li, C.R.; Wang, S.Q.; Cao, L.; Xie, S.S.; Yang, G.Z.; Zou, B.S.; Burda, C. Size and Structure Effect on Optical Transitions of Iron Oxide Nanocrystals. Phys. Rev. B 2005, 71, 125411. [CrossRef]

50. Sherman, D.M. The Electronic Structures of $\mathrm{Fe}^{3+}$ Coordination Sites in Iron Oxides: Applications to Spectra, Bonding, and Magnetism. Phys. Chem. Miner. 1985, 12, 161-175. [CrossRef] 
51. Grinberg, I.; West, D.V.; Torres, M.; Gou, G.; Stein, D.M.; Wu, L.; Chen, G.; Gallo, E.M.; Akbashev, A.R.; Davies, P.K.; et al. Perovskite Oxides for Visible-Light-Absorbing Ferroelectric and Photovoltaic Materials. Nature 2013, 503, 509. [CrossRef] [PubMed]

52. Schwaminger, S.P.; Surya, R.; Filser, S.; Wimmer, A.; Weigl, F.; Fraga-García, P.; Berensmeier, S. Formation of Iron Oxide Nanoparticles for the Photooxidation of Water: Alteration of Finite Size Effects from Ferrihydrite to Hematite. Sci. Rep. 2017, 7, 12609. [CrossRef] [PubMed]

53. Ciesielski, W.; Tomasik, P. Complexes of Amylose and Amylopectins with Multivalent Metal Salts. J. Inorg. Biochem. 2004, 98, 2039-2051. [CrossRef] [PubMed]

54. Wang, S.; Li, C.; Copeland, L.; Niu, Q.; Wang, S. Starch Retrogradation: A Comprehensive Review. Compr. Rev. Food Sci. Food Saf. 2015, 14, 568-585. [CrossRef]

55. Buazar, F.; Bavi, M.; Kroushawi, F.; Halvani, M.; Khaledi-Nasab, A.; Hossieni, S.A. Potato Extract as Reducing Agent and Stabiliser in a Facile Green One-Step Synthesis of ZnO Nanoparticles. J. Exp. Nanosci. 2016, 11, 175-184. [CrossRef]

56. Vigneshwaran, N.; Nachane, R.P.; Balasubramanya, R.H.; Varadarajan, P.V. A Novel One-Pot 'Green' Synthesis of Stable Silver Nanoparticles Using Soluble Starch. Carbohydr. Res. 2006, 341, 2012-2018. [CrossRef] [PubMed]

57. Chairam, S.; Poolperm, C.; Somsook, E. Starch Vermicelli Template-Assisted Synthesis of Size/Shape-Controlled Nanoparticles. Carbohydr. Polym. 2009, 75, 694-704. [CrossRef]

58. Galli, M.; Guerrini, A.; Cauteruccio, S.; Thakare, P.; Dova, D.; Orsini, F.; Arosio, P.; Carrara, C.; Sangregorio, C.; Lascialfari, A.; et al. Superparamagnetic Iron Oxide Nanoparticles Functionalized by Peptide Nucleic Acids. RSC Adv. 2017, 7, 15500-15512. [CrossRef]

59. Wu, W.; Jiang, C.; Roy, V.A. Recent Progress In Magnetic Iron Oxide-Semiconductor Composite Nanomaterials As Promising Photocatalysts. Nanoscale 2015, 7, 38-58. [CrossRef] [PubMed]

60. Redl, F.X.; Black, C.T.; Papaefthymiou, G.C.; Sandstrom, R.L.; Yin, M.; Zeng, H.; Murray, C.B.; O’Brien, S.P. Magnetic, Electronic, and Structural Characterization of Nonstoichiometric Iron Oxides at the Nanoscale. J. Am. Chem. Soc. 2004, 126, 14583-14599. [CrossRef] [PubMed]

61. Singh, S.; Barick, K.C.; Bahadur, D. $\mathrm{Fe}_{3} \mathrm{O}_{4}$ Embedded $\mathrm{ZnO}$ Nanocomposites for the Removal of Toxic Metal Ions, Organic Dyes and Bacterial Pathogens. J. Mater. Chem. A 2013, 1, 3325-3333. [CrossRef]

62. Mansour, A.M. Photocatalytic Degradation of Methylene Blue with Hematite Nanoparticles Synthesized by Thermal Decomposition of Fluoroquinolones Oxalato-Iron (III) Complexes. RSC Adv. 2015, 5, 62052-62061. [CrossRef]

63. Mardani, H.R.; Forouzani, M.; Ziari, M.; Biparva, P. Visible Light Photo-Degradation of Methylene Blue over Fe or Cu Promoted ZnO Nanoparticles. Spectrochim. Acta Part A 2015, 141, 27-33. [CrossRef] [PubMed] 